\title{
An Analysis of the Ways and Effects of Different Network Platforms in the Online Teaching of Biology in Middle School
}

\author{
Jie $\mathrm{Na}^{1 \mathrm{a}}$, Yanying Ding ${ }^{\mathrm{lb}}$
}

${ }^{I}$ School of Life Science, Liaoning Normal University, Dalian, Liaoning, China ajiena@lnnu.edu.cn

b1405941488@qq.com

\begin{abstract}
How to combine the characteristics of middle school biology and bring into full play the superiority of the network platform was of great significance to improve the online teaching effect of middle school biology. In this study, the methods of literature study, questionnaire survey and comparative analysis were used. Middle School biology teachers with online teaching experience were mainly investigated on the application of network platform in online teaching by questionnaire software. The results of the survey showed that the majority of teachers carefully chose to identify ways to use the network platform, and achieved the expected teaching effect, however, there was still a long way to go in improving students' biology accomplishment. Based on the research of the previous literature, this paper put forward the teaching suggestions of online teaching platform of middle school biology based on the three principles of OBE and PBL teaching mode, aiming at improving the teaching effect and providing reference for online teaching teachers of middle school biology to use the teaching platform.
\end{abstract}

Keywords: Network teaching platform, Online teaching, Teaching effect of Combination

\section{中学生物学线上教学中不同网络平台联用 途径与效果分析 \\ 那杰 $^{1 \mathrm{a}}$ 丁艳影 $^{1 \mathrm{~b}}$}

辽宁师范大学生命科学学院, 大连, 辽宁, 中国

ajiena@lnnu.edu.cn

b1405941488@qq.com

\section{摘要}

结合中学生物学学科特点、充分发挥各网络平台优势, 对提升中学生物学线上教学效果有重要意义。本研究采 用文献研究法、问卷调查法和比较分析法, 以具有网络教学经验的一线中学生物学教师为研究对象, 通过问卷 星编辑发布问卷, 对线上教学中网络平台的应用情况进行调查。调查结果显示, 大部分教师都认真地选择了使 用不同网络平台的联用途径, 并取得了预期的教学效果, 但是在提升学生生物学学科素养方面还有待进一步的 平台联用设计。结合前期文献的阅读研究, 提出了基于 OBE 理念三原则以及 PBL 教学模式的中学生物学线上 教学平台联用的教学建议, 旨在提升教学效果, 并为中学生物学线上教学教师进行教学平台的联用提供一定参 考。

关键词: 网络教学平台; 线上教学; 联用效果 


\section{1. 前言}

2020 年 2 月 4 日, 教育部发布了《关于在疫情防 控期间做好高校在线教学组织与管理工作的指导意 见》, 响应 “停课不停学” 号召, 线上教学 (Online Teaching) 全国范围内大规模开展。它突破地域限制, 只要通过电脑或手机就可以开展有效的教学活动, 是 教与学的一种方式转变, 成为了师生学习的必要手段, 其顺利进行有赖于稳定的网络教学平台支持。

网络教学平台 (Network Teaching Platform) 的应用推广可追溯到 1989 年创办的凤凰在线远程教 育课程。几年后 Learning Space-IBM 软件平台出现, 为学习者提供了自学、异步协作学习和虚拟课堂同步 交互学习三种在线学习模式。2013 年, 我国各种本地 化的网络教学平台如 “好大学在线”、“学堂在线”、 “爱课程” 等开始出现。随后, 企业沟通平台的介入 推动了教学实践创新。2020 年新冠疫情发生以来, 随 着全国范围内线上教学的进行, 各式网络教学平台首 次大规模应用于教学实践。应急状态下, 大部分网络 平台的教学功能目前尚处于初期发展阶段, 单一的网 络平台不能满足教学多样化的需要, 需要通过多平台 的选择与融合来保障教学效果。中学生物学是一门科 学性、系统性和开放性都很强的学科, 因此, 如何在 众多已开发、开放的网络教学平台中选出能有效落实 教学任务, 提升线上教学质量成为本研究关注的焦点。

\section{2. “停课不停学”背景下常见的网络教学平台}

全国各地在线教育整合了各种优质精品资源, 线 上教学工具种类丰富。根据影响范围, 网络教学平台 可分表 1 所示的四种类型。

表 1 新冠疫情下常见网络教学平台类型

\begin{tabular}{|l|l|}
\hline \multicolumn{1}{|c|}{ 平台类型 } & \multicolumn{1}{c|}{ 举例 } \\
\hline 国家级平台 & $\begin{array}{l}\text { 国家中小学网络云平台 } \\
\text { 中国教育电视台 CETV4 等 }\end{array}$ \\
\hline 省市级平台 & $\begin{array}{l}\text { 广州智慧教育公共服务平台 } \\
\text { 武汉教育云空中课堂等 }\end{array}$ \\
\hline 校级平台 & 无限宝、钉钉、cctalk 等 \\
\hline 社会平台 & Zoom、bilibili 直播等 \\
\hline
\end{tabular}

由于教师与学生所处地域不同等方面的限制, 线 上教学与线下教学不同, 因此不能简单地将线下的教 学方法、教学模式等原封不动地用于线上教学。教学 工作者或教师应充分了解不同教学平台的优势, 将教 学平台贯穿于课前、课中、课后三个阶段, 及时收集 学生学习反馈信息用于教学评价与反思, 优化教学设 计。但目前还没有一个能够满足线上教学中各种不同 需要的平台 ${ }^{[1]}$, 现行的四种类型的网络教学平台各有 特色。一线中学生物学教师可以结合学科特点, 通过 不同网络平台的联用, 取长补短、优势互补, 最大限 度地提升教学效率。

\section{3. 中学生物学线上教学中网络平台应用情况 的调查}

\section{1 . 调查实施}

2021 年 3 月-4 月, 以参加过线上教学的一线中 学生物学教师 (初中、高中) 为调查对象, 从三个维 度一一中学生物学线上教学平台联用现状、线上教学 平台联用途径、联用效果共 10 个问题设计调查问卷, 通过问卷星软件以线上方式发放问卷, 对现阶段中学 生物学线上教学网络平台联用现状进行调查, 最终收 回问卷 96 份, 其中有效问卷 95 份（初中 47 份, 高 中 48 份), 有效率为 $98.9 \%$ 。

\section{2 . 调查结果与分析}

调查结果显示， $63.16 \%$ 的教师使用了不同的网 络平台, 其余教师没有进行网络平台的联用。对未进 行多平台使用的教师进行调查, 发现其最常用教学平 台为单一的钉钉 (使用最多) 或微信。其中 $60 \%$ 的教 师认为多个平台联用对于教师本身来说有些复杂; 有 $22.86 \%$ 教师认为只要学生能听到自己讲就可以，联 用没有必要，担心给学生增加多平台切换的负担; $14.29 \%$ 的教师没有思考过可以多平台同时使用; 此 外教师也有一些其他原因从而未使用多个网络平台。 对进行网络教学平台联用的教师调查发现，仅 $25 \%$ 的 教师在线上教学最开始时就考虑过教学的需要而选 用多个网络平台; 多数教师开始线上教学时使用的是 单个平台, 后来渐渐发现单平台不能完全满足教学需 要才改换多平台。

教师的信息素养在选择使用网络平台时起到了 主要作用。调查表明部分教师信息素养意识是比较淡 薄。教师信息素养的提升是实现教育信息化顺应时代 发展的要求。新时代的中学教师首先应该掌握计算机 和互联网下网络平台的基本操作，应该主动提升自身 信息素养意识和能力; 从外部条件上来看, 教育部门 和学校应该进一步培训教师学科与信息技术整合的 课程教学能力以及信息技术工具的使用, 辅以比赛和 奖励政策，让教师在教学工作与生活中与时俱进，提 升信息素养，提高教学效率 ${ }^{[2]}$ 。

\section{2. 1. 平台联用依据与途径}

根据调查， $81.67 \%$ 教师选择平台联用的依据是 能否增进课堂上的有效互动; $71.67 \%$ 的教师注重学 生学习信息是否得到反馈以优化自己的教学设计; $65 \%$ 的教师会让教学平台贯穿课程的前、中、后三个阶段 确保完成自己的教学任务; 也有一些教师会根据学校 的选择或考虑平台能否支持不同方式增加学生的发 言几率如匿名发言、能否实时监控学生等进行平台的 选择。不同网络平台的联用选择上，50\%的教师选择 微信群和钉钉两平台的联用， $16.67 \%$ 的教师选择问 卷星、微信群和钉钉三平台的联用, 在其他联用途径 
的调查中未发现四个以上平台的联用。

调查中发现教师面对数量众多的网络平台不求 多而求精, 既能做到提升学生学习效果, 又能避免学 生在课堂上来回切换教学平台。不管选择怎样的联用 方式, 都是为了融合各平台的优势, 取长补短, 优化 教学平台组合, 提升教学效果。有的学校以单位形式 购买平台的相关服务如钉钉, 避免不同学科教师使用 平台不同带给学生课业之外的困扰, 尽量保证学生学 习在同一个平台完成, 学生端的操作简单高效。

\section{2. 2. 平台联用效果}

调查发现, 教师期待联用平台后, 学生合作探究 能力、学习主动性、发散思维能力将得到提升(图 1)。 不同网络平台联用后, 绝大多数教师认为联用后开阔 了学生的思路, 提升了学生对生物学概念的理解, 师 生之间的互动得到了加强; 多数教师认为得到了学生 学习效果的实时反馈 (图 2)。还有部分教师认为学生 收集、分析资料的能力得到了提升。

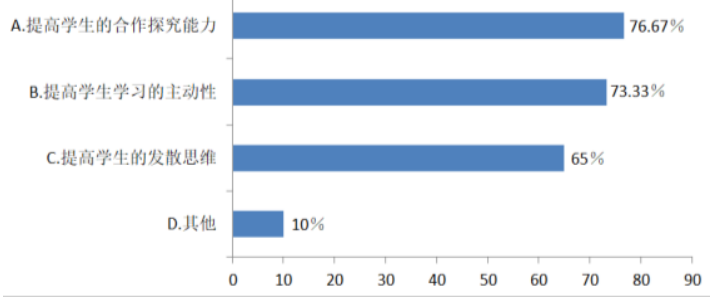

图 1 平台联用效果期望的调查结果

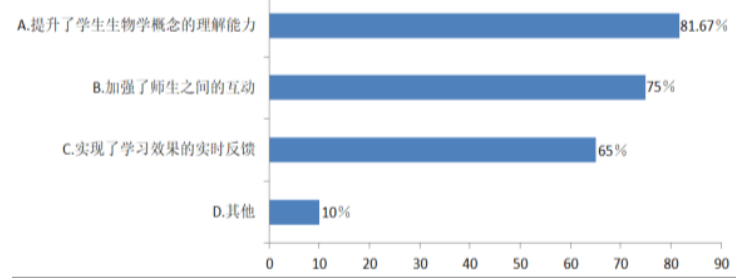

图 2 平台联用效果调查结果

\section{4. 中学生物学线上教学平台联用的教学建议}

\section{1. 基于 $O B E$ 理念三原则构建不同平台联用 模式}

OBE 理念是基于学习产出的让学生在教学过程中 取得学习成果, 再利用成果反馈改进原有的教学设计 的一种教育理念。线上教学平台联用符合其基本原则。

\subsection{1. 明确成果导向, 关注目标达成}

OBE 理念的成果导向原则是指教师所有的教学设 计都要以可测量的教学目标为前提, 设计灵活的教学 环节, 精细备课, 确保学生最后达成课程目标 ${ }^{[3]}$ 。该 原则的落实需要中学生物学教师提前调查学情并根
据新课改下课程目标设计具体的教学环节。问卷星能 够帮助中学生物教师完成学情调查, 还可以作为教学 设计中随堂检测环节的工具, 教师可以在课前将测试 内容通过问卷星完成编辑, 课堂进行到随堂检测环节 时直接发布, 即时评分并评估结果, 利于提高课堂效 率。便于联用的基础是：教师问卷编辑完成后，可以 直接发布在班级微信群或钉钉群里, 学生不用切换平 台作答, 操作简便。

\subsection{2. 强化学生中心，精设互动问题}

同线下教学一样, 在线上教学活动中, 不能简单 地播放教师录课或微课视频, 更需要教师开展精心设 计的以学生为中心的教学互动环节 ${ }^{[4]}$ 。生物学概念教 学往往会采用具有探索性、逻辑性、发散性的问题串 的形式设计研究活动, 帮助学生主动构建生物学概念, 利用科学概念来回答和解决实际问题 ${ }^{[5]}$ 。线上教学时 教师可在钉钉平台直播教学内容, 循序渐进引导学生 思考、回答问题。学生可通过与教师进行连麦, 通过 聊天消息面板输入文字或以密聊的形式发消息给教 师来回答问题。学生既可以在公麦搜集信息, 再通过 整理、分析、加工以获取补充自己的信息。密聊会将 学生的头像以及名称模糊掉, 可供性格内向学生选择。

\section{1. 3. 指向持续改进, 调整评价反馈}

持续改进原则要求对教学计划中预期教学成果 的总体实现情况进行多方位、多维度的评价, 基于评 价, 持续改进教学工作 ${ }^{[6]}$ 。线上教学中教师可以根据 各平台数据反馈和及时地评价教学效果, 调整教学内 容、教学进度等, 做到因材施教。教师在课后可以及 时通过线上平台查看学生视频观看时长以及聊天界 面学生的发言情况，对表现进行评价。同时可以把作 业要求以文字、图片等多种形式发送给学生。学生提 交作业后教师可通过语音或文字的形式逐一点评作 为评定班级优秀作业的依据。优秀作业的评定展示不 但可以让学生对自己的作业进行自评, 而且能够激发 学生斗志, 不断为使自己的作业成为优秀作业努力。

\section{2. 基于 $P B L$ 教学模式发挥不同平台联用效 果}

PBL 教学模式是以学生为教学主体, 以问题为教 学重点的一种教学模式, 通过小组合作开展研究和解 决问题的活动, 并提高学生自主学习、团队合作、解 决问题过程中的研究和创新等综合能力 ${ }^{[7]}$ 。

\section{2. 1. 拓宽学习空间, 发散生物学思维}

PBL 教学模式强调学生自主探究、分析和解决问 题的策略, 适于中学生物学中生物科学史的教学, 但 需要教师提供对学生知识建构的帮助。新人教版高中 生物必修 1 《分子与细胞》中 “细胞膜的结构和功能” 一节关于细胞膜结构的探索, 可设计学生分组, 利用 
线上教学中丰富的网络资源, 让学生在小组微信群中 收集、篎选资料, 分析科学家的探索历程, 体会科学 家的科研精神, 课堂最后以组为单位在钉钉平台进行 活动总结汇报。基于网络平台的 PBL 教学将学生的学 习内容从教材和参考书扩展到整个网络空间, 在网络 中收集解决问题所需的大量数据资料, 通过阅读和学 习拓展学生的体验, 丰富学生的思维广度和深度; 通 过对资料的分析和利用, 促进学生的批判性思维。

\section{2. 2. 创造探究环境, 引导学习自主性}

由于不能和线下教学一样实时监控学生, 提升学 生学习主动性就尤为重要。中学生物学线上教学中, 教师应该充分利用网络资源给学生带来创新而有趣 的学习体验。中学阶段的学生会有强烈的好奇心和探 究欲望, 因此, 教师必须为学生创造新奇环境, 使学 生有独立学习和探索的强烈冲动, 保持对课堂学习表 现出强烈的注意。以新人教版高中生物必修 1 《分子 与细胞》 “绿叶中色素的提取和分离” 实验为例, 教 师可提前设计并通过问卷星发布自主学习任务清单, 并设置小组, 小组任务清单中的内容全部完成后才可 以提交。自主学习任务清单内容为教师从不同维度设 计的实验结果分析, 如思考自变量对实验结果的影响 维度一一若实验组不加入碳酸钲, 与对照组相比, 胡 萝卜素、类胡萝卜素、叶绿素 $a$ 、叶绿素 $b$ 的含量会 怎样变化? 教师通过此教学设计为学生创设更多探 究思考情境, 启迪学生思维, 满足学生实验之外的探 究欲望, 进而逐步激发学生科学探究的热情, 引导学 生学习主动性。此外, 还可以设计脑洞环节, 比如让 学生思考 “在绿叶中色素的提取与分离实验中不能用 清水提取绿叶中的色素, 那么能不能提取花瓣中的色 素? ”, 通过设置类似的独出心裁的教学环节, 能够 让学生以好奇的心态去期待、参与每一节生物课。

\section{5. 结论}

本研究通过问卷调查发现中学生物学线上教学 中教师选择不同网络平台联用的比例高于单一平台, 联用平台有助于学生学习主动性、探究能力和思维水
平的提升。教师自身信息素养、学生学科素养的培养 等方面影响教师联用的选择。在提升学生生物学学科 素养方面还有待优化平台联用设计。所提出教学建议 期望可以为后疫情时代联合使用并优化组合不同的 教学平台, 更好地开展线上线下混合式教学提供参考。

\section{REFERENCES}

[1] Ma T, Qin Y, Fan WJ. Online teaching design and practice of data visualization course based on multi platform linkage flipping. Computer education, 2021, (1) : 42-44.

[2] Cai XJ. The significance and strategy of improving information literacy of primary and secondary school teachers. Information technology education in China. 2021(2):101-103.

[3] Feng YR, Jia QQ. Based on the idea of OBE, using the advantages of multiple platforms to complement each other to innovate a new online teaching mode. Science and technology economy guide, 2020, 28 (23): $132+131$.

[4] Zhao M. Design and practice of online teaching based on OBE concept-- Taking the course of process fluid machinery as an example. Modern educational equipment in China, 2020(15):75-77.

[5] Fu X, Yang WY. Using 5E Teaching Mode to design the teaching of 'cell differentiation'. Biology Bulletin, 2014,49(7):29-31.

[6] Zhu YJ, Liu C, Liu Y. Research and Practice on continuous improvement of "golden class" based on OBE concept. Beijing Education (Higher Education Edition), 2020 (5): 58-60.

[7] Dai GH, Wang M. Cultivation of students' thinking ability under PBL mode based on wechat platform. Journal of Huainan Vocational Technical College, 2020, 20 (1) : 79-81. 